\title{
Biochemical and Physiological Consequences of an Age-Related Increase in Acetylcholinesterase Activity at the Rat Neuromuscular Junction
}

\author{
Dean O. Smith and Mark Emmerling ${ }^{\text {a }}$ \\ Department of Physiology, University of Wisconsin, Madison, Wisconsin 53706
}

\begin{abstract}
Acetylcholinesterase (AChE) specific activity was assayed using diaphragm muscles obtained from mature adult (10 months) and aged (25-27 months) rats. Biochemical assays indicated significant age-related increases in the AChE specific activity of both noninnervated and innervated tissue. The different molecular forms of AChE were separated by velocity sedimentation and were further assayed. The agerelated increase was manifest primarily in the 105 (G4) form in both noninnervated and innervated tissue and also the $16 S$ (A12) form of the noninnervated samples. To ascertain more conclusively whether AChE activity in the end-plate junctional region of innervated tissue changed in the older rats, miniature end-plate currents (m.e.p.c.s) were recorded under voltage-clamp conditions before and after $\mathrm{AChE}$ inhibition. When AChE activity was inhibited by $10 \mu \mathrm{M}$ echothiopate or $1 \mathrm{~mm}$ methanesulfonyl fluoride, m.e.p.c. amplitudes and decay time constants increased in both age groups. The magnitude of these increases was larger in the older animals. However, calculations of the relative change in m.e.p.c. amplitudes after $A C h E$ inhibition indicated that less ACh was hydrolyzed by $A C h E$ in the older animals. Inhibition of AChE did not affect mean channel open time, which was estimated from spectral analyses of $\mathrm{ACh}$-induced membrane noise. These data indicate that the prolonged decay times in the older rats following $A C h E$ inhibition is quite likely due to an expanded field of postsynaptic $A C h$ receptors and not exclusively to a change in junctional $A C h E$.
\end{abstract}

At cholinergic synapses, hydrolysis of the neurotransmitter acetylcholine $(\mathrm{ACh})$ is catalyzed by acetylcholinesterase (AChE), which exists in multiple molecular forms (Massoulie and Bon, 1982). At the neuromuscular junction, this hydrolysis terminates transmitter action quickly, permitting only a small fraction of the ACh molecules to survive intact after 1 or 2 receptor attachments (Magleby and Stevens, 1972; Katz and Miledi, 1973; Hartzell et al., 1975; Kordas, 1977). Inhibition of AChE activity thus results in larger, prolonged end-plate currents.

Long-term inhibition of $\mathrm{AChE}$ activity can further result in pathologic changes at the neuromuscular junction. Presynaptic

\footnotetext{
Received Sept. 15, 1987; revised Dec. 23, 1987; accepted Jan. 8, 1988.

This work was supported by NIH Grant AG01572. Helpful discussions with Dr. A. O. W. Stretton and technical assistance provided by Mr. David Albright are gratefully acknowledged.

Correspondence should be addressed to Dr. Dean O. Smith, Department of Physiology, University of Wisconsin, 1300 University Avenue, Madison, WI 53706.

a Present address: Department of Neurology, University of Wisconsin, Madison, WI 53706.

Copyright (C) 1988 Society for Neuroscience $0270-6474 / 88 / 083011-07 \$ 02.00 / 0$
}

effects include increased numbers of motor nerve terminals (Glazer et al., 1978), reduced miniature end-plate potential (m.e.p.p.) amplitudes (Engel et al., 1973), and increased m.e.p.p. frequencies (Laskowski et al., 1975). These are accompanied by widened synaptic clefts (Engel et al., 1973), abnormal postsynaptic folds (Engel et al., 1973; Laskowski et al., 1975), and subsynaptic myopathy (Laskowski et al., 1975). This myopathy after $\mathrm{AChE}$ inactivation has been attributed to the prolongation of ACh lifetime and, thus, of junctional $\mathrm{Ca}^{2+}$ influx via the $\mathrm{ACh}$ receptors (Leonard and Salpeter, 1979).

Each of these morphologic changes following protracted AChE inhibition have also been observed at the neuromuscular junctions of aged rodents (Smith, 1979; Fahim et al., 1983; Smith and Rosenheimer, 1984; Rosenheimer and Smith, 1985). Therefore, it may be hypothesized that AChE decreases with age, resulting in prolonged ACh currents. Moreover, at the rat diaphragm, there is also an age-related increase in ACh leakage from the nerve terminals (Smith, 1984; Smith and Weiler, 1987) and in numbers of junctional and extrajunctional $\mathrm{ACh}$ receptors (Smith and Chapman, 1987). Together these phenomena might result in prolonged $\mathrm{ACh}$ currents, which ultimately lead to the observed $\mathrm{Ca}^{2+}$-dependent changes at the end-plate.

To test this hypothesis, AChE activity and its effect upon endplate currents were assayed in diaphragm tissue from mature adult and aged rats. Consistent with our hypothesis, the amount of ACh hydrolyzed by AChE decreased with age despite an apparent increase in junctional AChE activity. Surprisingly, however, these age-related changes did not affect end-plate currents, presumably because of a compensatory increase in the number of junctional ACh receptors.

\section{Materials and Methods}

\section{General experimental procedures}

All experiments were performed on the phrenic nerve-diaphragm muscle of Fischer 344 rats obtained from the aged animal colonies under contract to the National Institute on Aging (Harlan-Sprague-Dawley). Males aged 10 ("mature adult") and 25 to 27 ("aged") months were chosen. The average $( \pm$ SE) weights were $369( \pm 19)$ and $376( \pm 15) \mathrm{gm}$, respectively; the corresponding wet weight/protein ratios were 6.5 and 6.3. There were no significant differences in tissue weight or protein content.

The rats were anesthetized with chloral hydrate $(2.8 \mathrm{mmol} / \mathrm{kg}$, i.p. $)$, and each hemidiaphragm with the associated phrenic nerve was dissected. The tissue was then placed in saline solution with the following constituents (mM): $\mathrm{NaCl}(124), \mathrm{KCl}(5.1), \mathrm{MgCl}_{2}$ (1.3), $\mathrm{KH}_{2} \mathrm{PO}_{4}$ (1.22), $\mathrm{NaHCO}_{3}$ (25.5), $\mathrm{CaCl}_{2}$ (2), and glucose (10.2), pH 7.4. Fresh saline, aerated with $95 \% \mathrm{O}_{2}-5 \% \mathrm{CO}_{2}$, circulated over the tissuc at a ratc greater than $10 \mathrm{ml} / \mathrm{min}$; oxygen saturation was maintained at greater than $80 \%$ $(608 \mathrm{~mm} \mathrm{Hg}$ ). 


\section{Extraction and analysis of $A C h E$}

Hemidiaphragm tissue to be assayed for AChE activity was further dissected into innervated and noninnervated strips (Smith and Weiler, 1987). This permitted distinction between AChE activity associated with junctional (innervated) and extrajunctional (noninnervated) regions on the muscle membrane.

To extract AChE activity, the freshly dissected muscle strips were homogenized in $1 \mathrm{ml}$ of borate- $\mathrm{NaOH}$ buffer $(\mathrm{pH} 8.8)$ containing $1 \mathrm{~mm}$ ethylenediaminetetraacetic acid (EDTA), $1 \mathrm{M} \mathrm{NaCl}$, and $0.5 \%$ Triton $\mathrm{X}-100$. They were then frozen immediately and stored at $-70^{\circ} \mathrm{C}$ for subsequent analysis. Upon thawing, they were centrifuged at $50,000 \times$ $g$ for $30 \mathrm{~min}$ at $4^{\circ} \mathrm{C}$, and aliquots of the supernatant were taken for assays of total $\mathrm{AChE}$ activity and protein content and for analysis of AChE forms.

AChE activity was assayed using the radiometric method of Johnson and Russell (1975), in which ${ }^{3} \mathrm{H}$-ACh (Amersham, TRA277) is converted to ${ }^{3} \mathrm{H}$-acetate. This highly sensitive assay uses substrate concentrations well below those required to achieve maximum initial reaction velocity $\left(V_{\max }\right)$. It is insensitive to butyrylcholinesterase (Rand and Huff, 1986) and is, therefore, specific for AChE. Indeed, $10^{-5} \mathrm{M}$ BW284C51, a specific AChE inhibitor, was found to inhibit the assay completely, confirming the assay's specificity. The enzyme activity is expressed as $V_{\max } / K_{m}$, where $K_{m}$ is the Michaelis-Menten constant, using calculation procedures described by Rand and Johnson (1979).

Protein determinations utilized a modification of the Lowry method (Wang and Smith, 1979), which is suitable for samples containing Triton $\mathrm{X}-100$. BSA was used as the protein standard.

AChE forms were separated on 4-20\% linear sucrose gradients made up in borate- $\mathrm{NaOH}$ extraction buffer. This involved centrifugation $\left(\omega^{2} t\right.$ $=7.74 \times 10^{11}$ radians $^{2} \mathrm{sec}$ ) of $100 \mu \mathrm{l}$ samples overnight at $4^{\circ} \mathrm{C}$. The sucrose gradients were fractionated, and each fraction assayed for $\mathrm{AChE}$ activity. Identification of AChE forms was based on their sedimentation values (S-value) determined by relating the positions of AChE peaks on gradients to the positions of proteins with known S-values (galactosidase, 16S; catalase, 11.3S; and alkaline phosphatase, 7.4S). The $4 \mathrm{~S}$ and $6 \mathrm{~S}$ forms are not clearly separated by this method, so the single peak is designated as " 4 \& $6 \mathrm{~S}$ " AChE. Measurement of the amount of enzyme activity associated with the AChE forms involved curve decomposition utilizing the method developed by Dreyfus et al. (1984). Briefly, this involves fitting a bell-shaped curve to the peak of AChE activity on the gradient and measuring the area underneath.

\section{Electrophysiology}

Voltage-clamp recordings. Spontaneous miniature end-plate currents (m.e.p.c.s) and ACh-induced membrane current fluctuations were recorded in voltage-clamped preparations at room temperature $\left(23^{\circ} \mathrm{C}\right)$. Microelectrodes for recording membrane potential and passing current were filled with $3 \mathrm{M} \mathrm{KCl}$ and $2 \mathrm{M} \mathrm{K}$-acetate, respectively. Tip resistances for both types were between 10 and $20 \mathrm{M} \Omega$. The voltage microelectrode was inserted initially under visual guidance, and the position was then adjusted until m.e.p.p. rise times were $<1 \mathrm{msec}$. After locating a suitable recording site with the voltage microelectrode, the current-passing microelectrode was inserted within $<30 \mu \mathrm{m}$; m.e.p.p. rise times were equally fast with both electrodes.

In the fluctuation-analysis experiments, a third microelectrode, with about a $70 \mathrm{M} \Omega$ tip resistance, containing $2 \mathrm{M} \mathrm{ACh}$ was positioned between the 2 voltage-clamp electrodes at a height of about $50-100 \mu \mathrm{m}$ above the muscle surface. This distance permitted a gradual rise in $\mathrm{ACh}$ concentration at the receptors. Iontophoretic currents were from an isolated source connected to a separate ground and were monitored. A backing current of -5 to $-10 \mathrm{nA}$ was usually adequate to prevent significant ACh leakage from this electrode. Conversely, simply turning off this current usually allowed sufficient $\mathrm{ACh}$ ejection, although currents as high as $50 \mathrm{nA}$ were occasionally used.

The voltage-clamp electrodes were connected to a voltage-clamp amplifier (Dagan 8500). Currents were recorded through an active virtual ground associated with the instrument. Under voltage clamp at -80 $\mathrm{mV}$ membrane potential, the gain was adjusted until the voltage change in response to a command pulse was indistinguishable from the actual command value and m.e.p.p.s were not visible.

The m.e.p.c. records were digitized at a $25 \mathrm{kHz}$ sampling rate and subsequently analyzed using a PDP $11 / 23$ computer. The time constant of the decay phase was estimated by fitting an exponential curve using least-squares techniques.
Records for fluctuation analysis were passed through an 8-pole Butterworth active filter (Frequency Devices $901 \mathrm{~F}$ ) with a $1000 \mathrm{~Hz}$ lowpass cutoff. Current levels and fluctuations were monitored at low and high gain, respectively, and were digitized at a $2000 \mathrm{~Hz}$ sampling rate. Individual segments of 512 points were examined visually, and if they were free from spurious signals (such as m.e.p.c.s), the Fourier transform was computed to yield a 2 -sided spectral density function. To reduce leakage, a cosine taper was then applied to the data (Bendat and Piersol, 1971). The average of 20 transformed sample segments was obtained for each analysis.

At each site, an average control spectrum of background noise was first obtained. ACh was then applied, and after the membrane response had stabilized, the spectrum of ACh-induced noise was obtained. At low frequencies the spectral density of the background noise was usually $<10^{-23} \mathrm{~A}^{2}$ sec. The control spectrum was then subtracted to remove background contributions from nonreceptor membrane currents and electronic noise. This difference spectrum was then analyzed further.

Parameters of the spectral density function were estimated by fitting a Lorentzian curve to the data using nonlinear, iterative least-squares techniques. The Lorentzian is described by $S(f)=S(0) /\left[1+\left(f / f_{c}\right)^{2}\right]$, where $S(f)$ is the power spectral density at frequency $f, f_{c}$ is the half-power frequency, and $S(0)$ is the spectral density at zero frequency. The time constant $(t)$, representing mean channel open time, was calculated from the formula $t=f_{c} / 2$.

\section{Statistical analysis}

All statistical tests were based upon routine 2-tailed procedures. Computed SEs of the ratios of 2 variables were calculated using techniques presented by Finney (1978).

\section{Results}

\section{$A C h E$ assays}

Specific activity of $\mathrm{AChE}$ was assayed in innervated and noninnervated regions of tissue derived from 5 animals of each age group. Data were obtained from the homogenate supernatant and from the samples after they had been separated into the different molecular forms by velocity sedimentation on a sucrose density gradient. Representative profiles of AChE specific activities after sedimentation are shown in Figure 1.

Total AChE specific activities are summarized in Figure 2. Consistent with results of a previous study (Smith, 1984), analysis of the homogenate supernatant indicated a significant agerelated increase in $\mathrm{AChE}$ specific activity in the noninnervated, but not the innervated, regions of the muscle fibers (Fig. $2 A$ ). After separation by velocity sedimentation, the specific activities of the different fractions for each gradient were summed to obtain total values. These data revealed significantly greater AChE specific activity in both noninnervated and innervated regions of tissue from the older animals (Fig. $2 B$ ). These increases of 88 and $36 \%$, respectively, were significant at the 0.05 level. Presumably, some component in the $50,000 \times g$ supernatant is excluded from the sucrose gradient (probably in pellet form) during centrifugation. This may be an indication that a smaller percentage of $\mathrm{AChE}$ exists as an insoluble form in tissue from the older animals.

AChE specific activity of the discrete forms was further assayed. The results, presented in Figure 3, demonstrate significant (0.02 level) age-related increases in the specific activity of the $10 \mathrm{~S}$ forms of innervated and noninnervated regions. In the aged rats, these specific activities increased by 81 and $128 \%$, respectively. Moreover, there was a $132 \%$ increase in specific AChE activity associated with the $16 \mathrm{~S}$ form in noninnervated samples from the older animals; this is significant at the 0.01 level. Thus, the age-related increases in AChE specific activity may be attributed in both noninnervated and innervated regions of the 


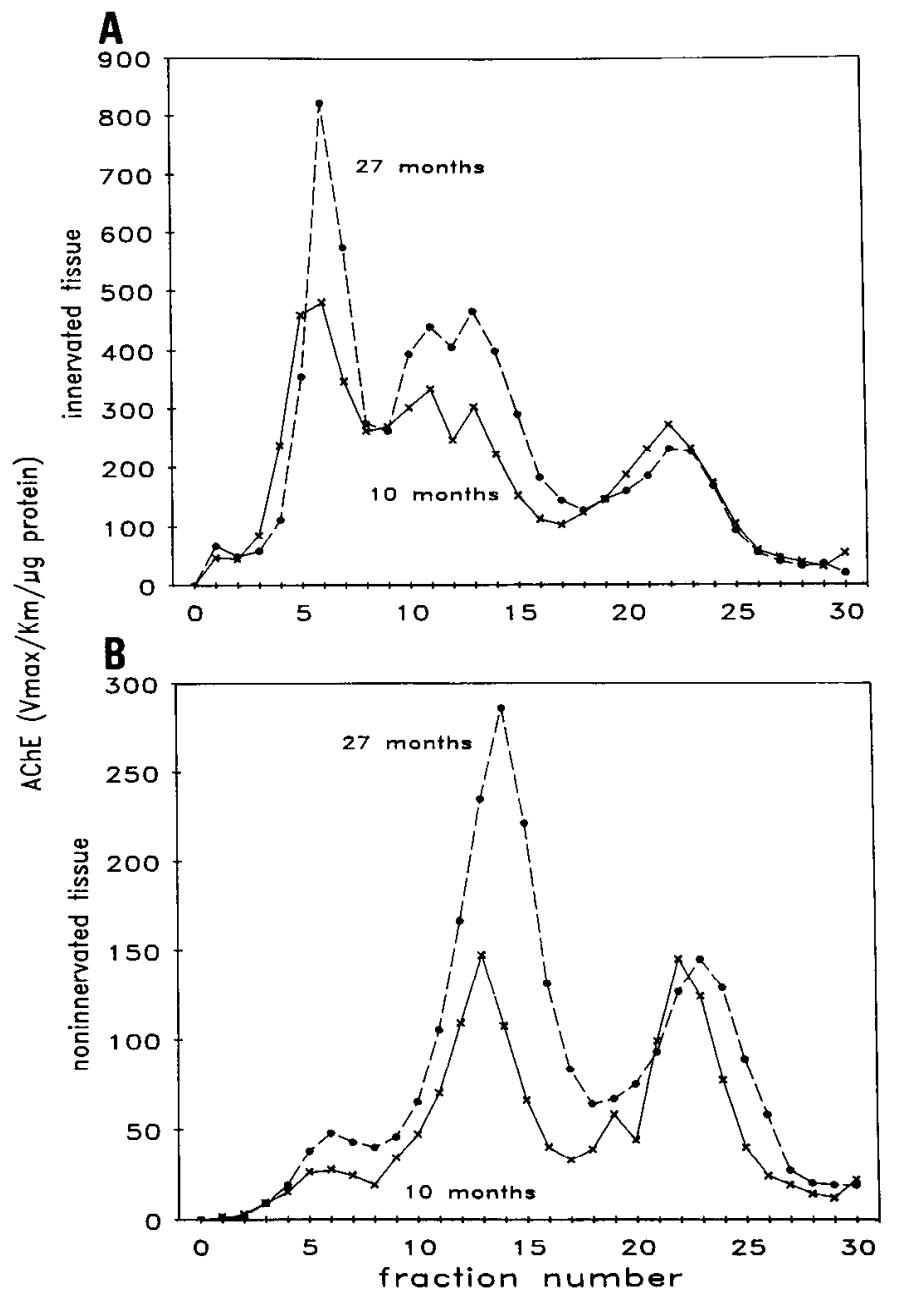

Figure 1. AChE specific activities in fractions obtained following velocity sedimentation. These representative profiles were obtained from innervated $(A)$ and noninnervated $(B)$ tissue from the diaphragm muscle of one animal of each age group.

muscle fibers primarily to elevated levels of the $10 \mathrm{~S}$ form and, in the noninnervated regions, also the $16 \mathrm{~S}$ form.

Since protein content and muscle weight do not differ significantly with age in the diaphragm muscle (Smith and Weiler, 1987), these data indicate increased total AChE activity. Changes in specific activity of some, but not all, molecular forms of the enzyme further indicate that increased AChE specific activity was not simply related to an overall change in muscle protein.

Measurements obtained from the noninnervated muscle regions clearly represent an age-related increase in extrajunctional AChE specific activity. The innervated tissue, though, contains AChE located in both junctional and extrajunctional regions. Similar age-related increases in the $10 \mathrm{~S}$ forms measured in noninnervated and innervated regions (Fig. 3) draw attention to the possibility that increased $A C h E$ specific activity measured in the innervated tissue samples may not be specific for the junctional components. Therefore, the specific activity of the junctional contribution was estimated by subtracting the average values of total specific activity on the sucrose gradient assayed in noninnervated samples on a per protein basis from the corresponding innervated data (Fig. $2 B$ ).

The resulting calculations (Table 1) indicated an $11 \%$ increase
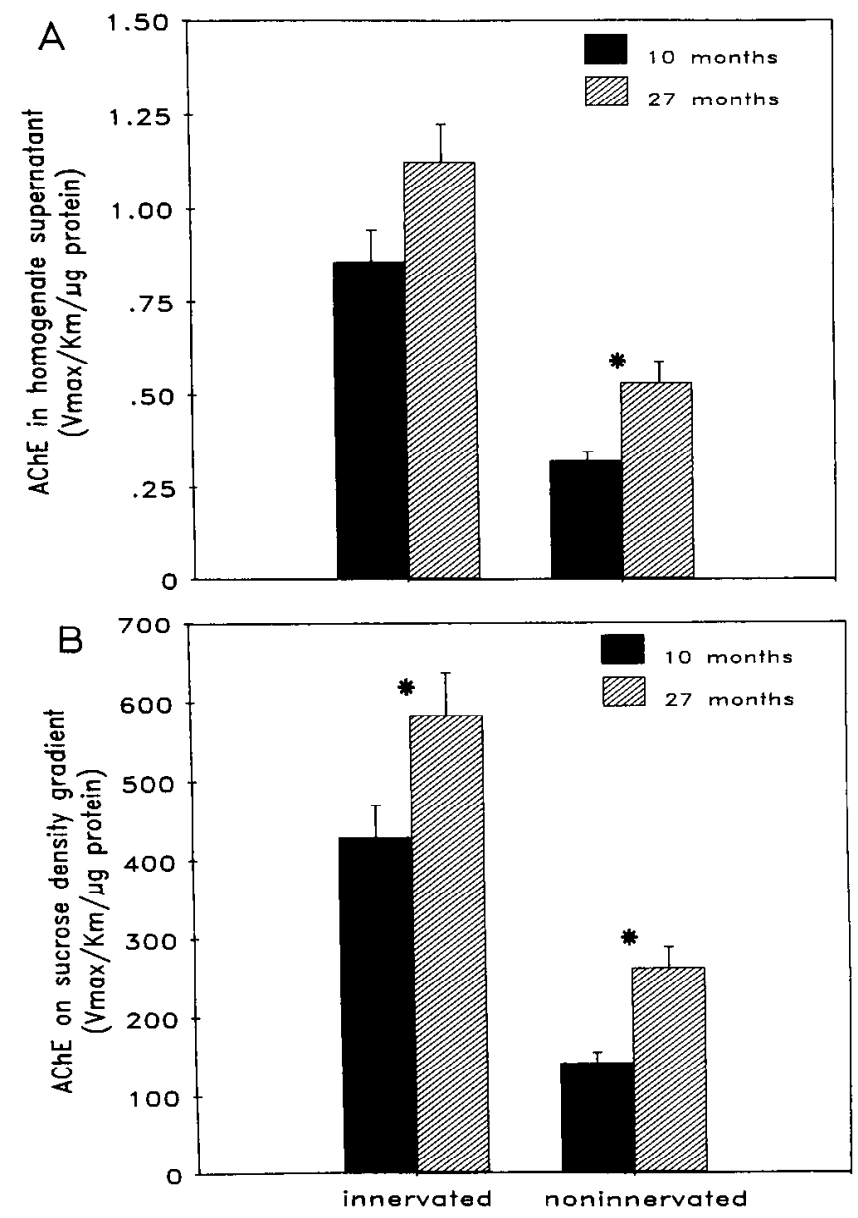

Figure 2. AChE specific activity in mature adult ( 10 months) and aged (27 months) rats. Average values $(+\mathrm{SE})$ of data obtained from innervated and noninnervated regions of diaphragm muscle from 5 animals of each age group are shown. $A$, Specific activities measured in the homogenate supernatant. $B$, Sum of all specific activities measured on the sucrose gradient. Asterisks indicate that the corresponding values for the 2 age groups are significantly different at the 0.05 level.

in the junctional component of $\mathrm{AChE}$ specific activity with age, but this is not significant statistically. Similar calculations for the $10 \mathrm{~S}$ and the $16 \mathrm{~S}$ forms were also not significantly different. Furthermore, the modest change in enzyme levels may be related to a corresponding increase in end-plate area, for the junctional area staining histochemically for AChE was found to increase by about $23 \%$ in this preparation (Rosenheimer and Smith, 1985). When AChE specific activity is divided by endplate area, a small (but insignificant) decrease in end-plate specific AChE density is obtained during aging (Table 1).

These data suggest that the apparent age-related increase in total AChE specific activity in innervated tissue may be attributed parsimoniously to greater specific activity of the associated extrajunctional component. Moreover, there does not appear to be any change in junctional AChE density; indeed, there may even be a small decrease with age. Rather than base conclusions solely on these calculations, which assume a population of $\mathrm{AChE}$ directly involved with synaptic activity, further experiments using electrophysiologic techniques were performed to assess possible changes in junctional AChE activity on end-plate currents. 


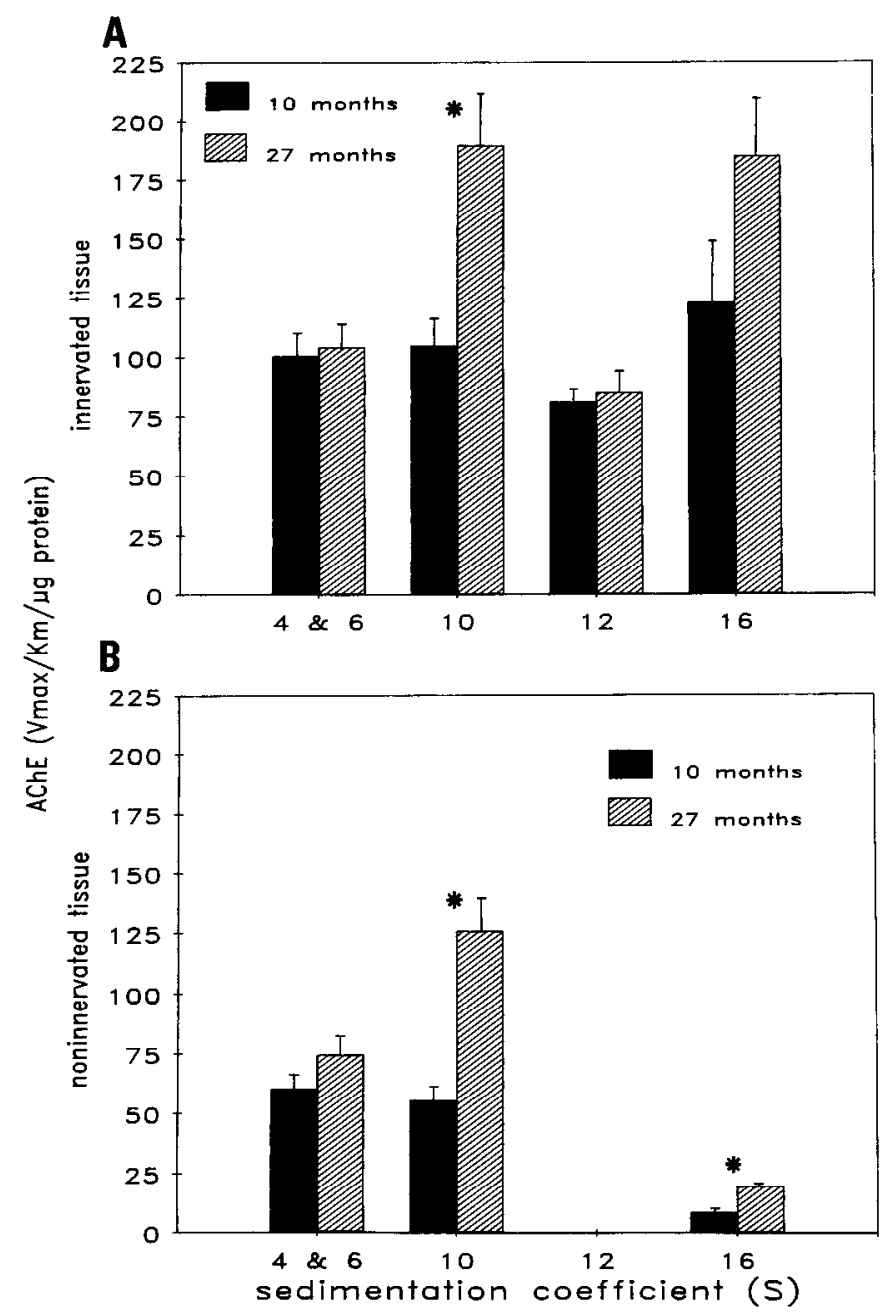

Figure 3. Specific activities of specific molecular forms of AChE. Average values $(+\mathrm{SE})$ of data obtained from innervated $(A)$ and noninnervated $(B)$ diaphragm muscle tissue from 5 animals of each age group are presented. The asterisks indicate that the corresponding values are significantly different at the 0.05 level.

\section{Miniature end-plate currents}

If junctional AChE activity were, indeed, greater at the endplates of aged animals, an age-related increase in the rate of ACh hydrolysis might be expected. Conversely, the effects of an anti-cholinesterase agent might be greater in the older rats. This latter possibility was tested by measuring m.e.p.c.s before and after addition of AChE inhibitors.

Under voltage-clamp, m.e.p.c. amplitudes, time-to-peak, and decay times were analyzed digitally, as illustrated in Figure 4, before and after addition of echothiopate. In these experiments, echothiopate, $10 \mu \mathrm{M}$, was tested and found to inhibit AChE activity by $>95 \%$.

The resulting effects on m.e.p.c.s are summarized in Table 2. Before adding echothiopate, m.e.p.c.s were similar for both age groups. As expected, inhibition of $\mathrm{AChE}$ activity consistently resulted in larger, prolonged m.c.p.c.s. Howcver, thc magnitudes of the increases in both amplitude and decay time, expressed as the ratios of measurements after/before echothiopate (Table 2 ), were significantly greater in the older animals. Furthermore, there was a significant increase in the time from m.e.p.c. onset to peak amplitude in the 26 month, but not the 10 month, animals.

Similar results were obtained from further experiments in which m.e.p.c. data were recorded before and after addition of a different AChE inhibitor, $1 \mathrm{~mm}$ methanesulfonylfluoride(MSF). The average ( $\pm \mathrm{SE}$ ) amplitudes measured from sites in 3 different animals of each age group increased by $25 \%( \pm 6 \%)$ and $64 \%$ $( \pm 12 \%)$ in 10 and 26 month animals, respectively. This agerelated difference is significant at the 0.05 level. The corresponding increases in decay time constants were $28 \%( \pm 5 \%)$ and $42 \%$ $( \pm 4 \%$ ). These 2 values are different at the 0.1 significance level.

Comparable experiments were also performed using tissue from 2 animals of each age group using $30 \mu \mathrm{M}$ neostigmine methylsulfate to inhibit AChE activity. Since its effect is reversible, the neostigmine was maintained in the bathing solution for the duration of the experiment. In 10 month animals, amplitude and decay time constant increased as expected. However, they decreased by $13-22 \%$ in each 26 month rat. A shortening of m.e.p.c. time course in the presence of $30 \mu \mathrm{M}$ neostigmine has similarly been detected in uncurarized frog muscle (Katz and Miledi, 1973). This observation was not pursued further, but it clearly illustrates the need for caution when using these drugs with aged animals (Smith and Chapman, 1987).

To determine the relative rates of $\mathrm{ACh}$ clearance by $\mathrm{AChE}$, m.e.p.c. amplitudes were measured at a time point common to all conditions, namely, $0.5 \mathrm{msec}$ after the onset (Table 2). The relative fraction of $\mathrm{ACh}$ hydrolyzed, $P$, at this time can be estimated from these data using the formula

$$
\text { amplitude }_{(+)} \text {amplitude }_{(-)}=1-P_{(+)} / 1-P_{(-)},
$$

where the subscripts indicate before $(+)$ or after $(-) \mathrm{AChE}$ inhibition (see Katz and Miledi, 1973). When AChE is inhibited, $P_{(-)}=0$. The values of $P_{(+)}$are 15.1 and $6.3 \%$ in the 10 and the 26 month animals, respectively. It thus appears that the rate at which AChE limits the amount of ACh reaching the postsynaptic receptors is decreased with age.

Table 1. End-plate specific AChE activity

\begin{tabular}{|c|c|c|c|c|c|}
\hline $\begin{array}{l}\text { Age } \\
\text { (mo.) }\end{array}$ & $\begin{array}{l}\text { Innervated } \\
\text { specific activity } \\
\left(V_{\max } / K_{m} / \mu \mathrm{g}\right. \\
\text { protein }) \\
\end{array}$ & $\begin{array}{l}\text { Noninnervated } \\
\text { specific activity } \\
\left(V_{\max } / K_{m} / \mu \mathrm{g}\right. \\
\text { protein) } \\
\end{array}$ & $\begin{array}{l}\text { End-plate } \\
\text { specific AChE } \\
\text { activity } \\
\left(V_{\max } / K_{m} / \mu \mathrm{g}\right. \\
\text { protein) }\end{array}$ & $\begin{array}{l}\text { End-plate area } \\
\left(\mu \mathrm{m}^{2}\right)\end{array}$ & $\begin{array}{l}\text { End-plate } \\
\text { specific AChE } \\
\text { density } \\
\left(V_{\max } / K_{m} / \mu \mathrm{g}\right. \\
\left.\text { protein } / \mu \mathrm{m}^{2}\right)\end{array}$ \\
\hline 10 & $428.7 \pm 39.9^{*}$ & $139.6 \pm 13.6 \dagger$ & $289.1 \pm 42.1$ & $639.9 \pm 45.6$ & $0.45 \pm 0.07$ \\
\hline 27 & $582.5 \pm 53.5^{*}$ & $261.9 \pm 27.1 \dagger$ & $320.6 \pm 60.6$ & $788.9 \pm 38.7$ & $0.41 \pm 0.08$ \\
\hline
\end{tabular}

Average $( \pm \mathrm{SE})$ of values obtained from at least 5 different animals of each age group. Fnd-plates areas are from Rosenheimer and Smith (1985). Superscripts indicate that the corresponding values are different at $0.05\left(^{*}\right)$ or $0.01(\dagger)$ significance levels. 


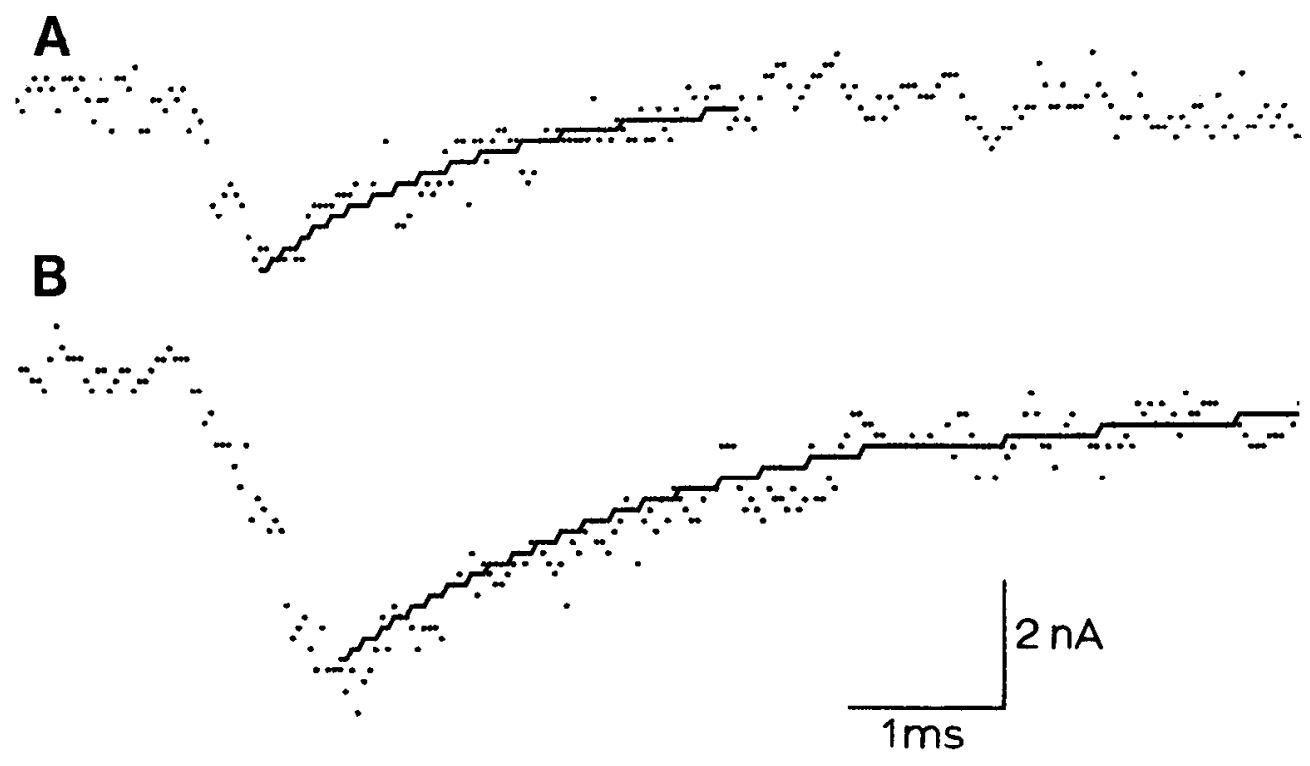

Figure 4. Effects of AChE inhibition on miniature end-plate currents. Membrane potential was clamped at -80 $\mathrm{mV}$. Control records $(A)$ were obtained initially. Echothiopate $(10 \mu \mathrm{M})$ was then added; at this concentration, $>95 \%$ of the AChE activity is irreversibly inhibited. After 20-30 min, it was washed out by rinsing thoroughly (10-15 min) with fresh saline solution, and miniature end-plate currents were again recorded $(B)$. These sample records are from a rat aged 26 months. The exponential curve was fit by the method of least squares.

\section{Single-channel properties}

If AChE activity were greater in the older animals and all other factors were the same, then inhibition of the AChE should result in equal decay times in both age groups. Since decay times were longer in the 26 month animals after AChE inhibition, some factor other than $\mathrm{AChE}$ must be influencing decay under these conditions. A likely possibility is altered single-channel gating kinetics associated with either age of the animal or addition of the anti-AChE compounds, echothiopate, or MSF.

Therefore, to test this possibility, mean channel open time was estimated from the spectral density of ACh-induced noise obtained from 8 different sites in each age group before and after addition of $10 \mu \mathrm{M}$ echothiopate. Sample spectra are shown in Figure 5, and the results are summarized in Table 2. There were no significant changes in mean channel open time, and this possibility was rejected. Furthermore, there were no indications in these data of significant age-related changes in singlechannel conductance.

\section{Discussion}

The main conclusion of this study is that total AChE activity at the rat diaphragm neuromuscular junction increases with age.
This is expressed biochemically as increased specific activities of the $10 \mathrm{~S}$ and the $16 \mathrm{~S}$ forms in noninnervated and innervated regions of tissue. Moreover, there is a more pronounced increase in maximum m.e.p.c. amplitude in older rats following AChE inhibition, indicating a relatively greater role for AChE in limiting the postsynaptic response in the aged animals. However, the density of end-plate specific $\mathrm{AChE}$ and the proportion of ACh hydrolyzed at a common time point ( $0.5 \mathrm{msec})$ after m.e.p.c. onset do not increase in the aged animals. Therefore, despite the biochemical measurements of an apparent increase in AChE specific activity in innervated tissue, there is an apparent decrease in the amount of the enzyme hydrolyzing junctional ACh.

However, the age-related reduction does not change m.e.p.c.s under normal conditions. This possibly reflects a rather modest role of $\mathrm{AChE}$ in $\mathrm{ACh}$ removal from the end plates of rat diaphragm. The effects of AChE inhibition on m.e.p.c. amplitude and decay time constant in rats of both age groups were considerably less than comparable data obtained from frog (cf. Magleby and Stevens, 1972; Katz and Miledi, 1973; Kordas, 1977). At most, a 2-fold increase in these parameters was observed in rat, while 4- to 7-fold increases are usually measured in frog. This discrepancy may reflect species-specific differences in AChE efficiency and, more specifically, in end-plate architecture. Un-

Table 2. Effects of echothiopate on miniature end-plate currents and single channel gating kinetics

Miniature end-plate currents

\begin{tabular}{|c|c|c|c|c|c|}
\hline \multirow[b]{2}{*}{ Treatment } & \multicolumn{4}{|c|}{ Miniature end-plate currents } & \multirow[b]{2}{*}{$\begin{array}{l}\text { Mean channel } \\
\text { open time } \\
\text { (msec) }\end{array}$} \\
\hline & $\begin{array}{l}\text { Amplitude } \\
\text { at } 0.5 \text { msec } \\
\text { (nA) }\end{array}$ & $\begin{array}{l}\text { Maximum } \\
\text { amplitude } \\
\text { (nA) }\end{array}$ & $\begin{array}{l}\text { Time to peak } \\
(\mathrm{msec})\end{array}$ & $\begin{array}{l}\text { Decay time } \\
\text { (msec) }\end{array}$ & \\
\hline \multicolumn{6}{|l|}{ Adult animals (10 month) } \\
\hline Before echothiopate & $2.37 \pm 0.23$ & $3.84 \pm 0.17^{a}$ & $0.81 \pm 0.07$ & $1.52 \pm 0.10^{e}$ & $1.65 \pm 0.13$ \\
\hline After echothiopate & $2.79 \pm 0.26$ & $5.46 \pm 0.25^{a}$ & $0.98 \pm 0.08$ & $1.95 \pm 0.10^{\circ}$ & $1.68 \pm 0.21$ \\
\hline Ratio (after/before) & $1.17 \pm 0.16$ & $1.42 \pm 0.11^{b}$ & $1.21 \pm 0.14$ & $1.28 \pm 0.10^{g}$ & $1.02 \pm 0.15$ \\
\hline \multicolumn{6}{|l|}{ Aged animals (26 month) } \\
\hline Before echothiopate & $2.82 \pm 0.36$ & $3.95 \pm 0.21^{c}$ & $0.70 \pm 0.08^{d}$ & $1.64 \pm 0.17^{f}$ & $1.93 \pm 0.13$ \\
\hline After echothiopate & $3.01 \pm 0.45$ & $7.10 \pm 0.56^{c}$ & $1.18 \pm 0.15^{d}$ & $3.37 \pm 0.27^{f}$ & $2.43 \pm 0.44$ \\
\hline Ratio (after/before) & $1.07 \pm 0.21$ & $1.80 \pm 0.17^{b}$ & $1.69 \pm 0.29$ & $2.06 \pm 0.27^{g}$ & $1.26 \pm 0.24$ \\
\hline
\end{tabular}

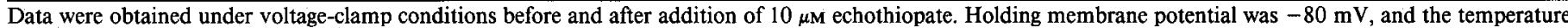

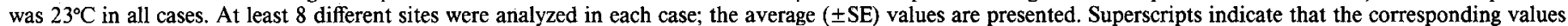
are different at the $0.08(b), 0.05(a, f), 0.02(d, g)$, or $0.01(c, e)$ significance levels. 

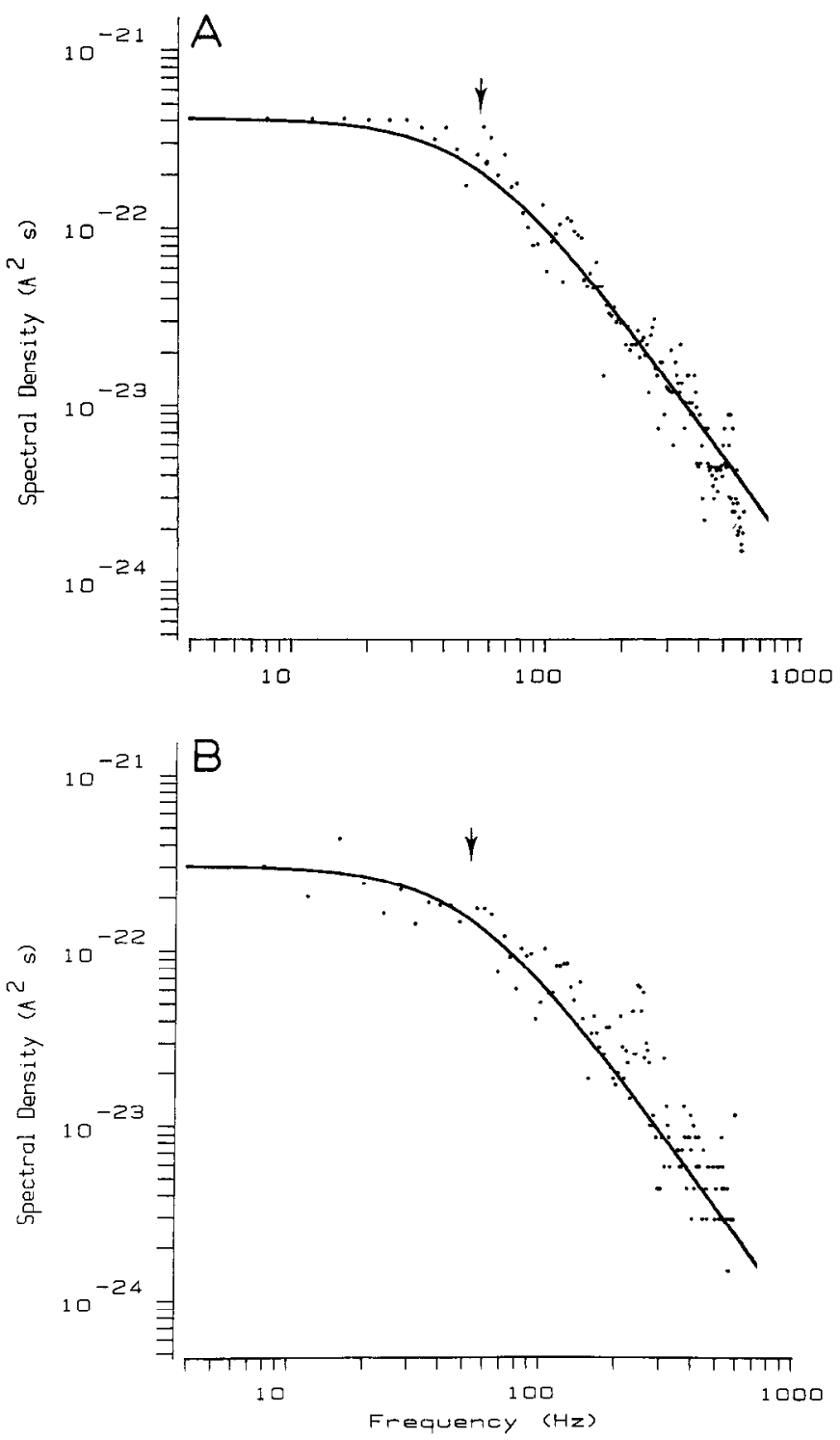

Figure 5. Spectral density of ACh-induced membrane noise. A sample spectrum obtained from a cell clamped at $-80 \mathrm{mV}$ membrane potential and at $23^{\circ} \mathrm{C}$ during iontophoretic application of $\mathrm{ACh}$ is shown in $A$. Inmediately after these data were obtained, $10 \mu \mathrm{M}$ echothiopale was added to the bath for $15 \mathrm{~min}$ to inhibit AChE activity irreversibly. The echothiopate was then washed away, and $\mathrm{ACh}$-induced membrane noise was again recorded; the resulting spectrum is shown in $B$. The Lorentzian curves were fit by an iterative nonlinear procedure. Location of the halfpower frequencies $\left(f_{c}\right)$ are indicated by the arrows. The estimated mean channel open times $(t)$ were $2.89 \mathrm{msec}(A)$ and $2.81 \mathrm{msec}(B)$. These examples were obtained from an animal aged 26 months.

der normal conditions, it might be inferred that diffusion apparently plays a greater role in clearance of $\mathrm{ACh}$ in rat than in frog.

Although inhibition of AChE activity has a demonstrably greater effect on m.e.p.c. decay time in the older animals, there is no significant age-related difference when $\mathrm{AChE}$ activity is intact (Table 2). This result merits closer attention. If an agerelated increase in AChE activity were the only difference between the 2 age groups, m.e.p.c. decay times and amplitudes would presumably be smaller in the older animals before AChE inhibition, and they would then become equal in magnitude after addition of an anti-cholinesterase. Since this was not the observed result, some other factor must also be affecting m.e.p.c.s. Furthermore, the data indicate that this does not involve altered single-channel open times.

Following AChE inhibition, m.e.p.c. decay time is governed primarily by the rate of ACh diffusion away from the receptors (Katz and Miledi, 1973). Thus, slower decay times in aged rats might manifest slower $\mathrm{ACh}$ diffusion rates in these animals (Smith, 1982). If diffusion were uniformly slower throughout the synaptic cleft, the time to peak amplitude might also be longer in the older preparations. This was not the case, though. Alternatively, the rate of $\mathrm{ACh}$ diffusion from the receptor field would also be expected to decrease if there were increased numbers of $\mathrm{ACh}$ receptors. Indeed, following $\mathrm{AChE}$ inhibition, m.e.p.c. decay times have been shown to increase proportionally with an increased availability of receptors to which the ACh can bind (Katz and Miledi, 1973). The results of this study are consistent with this conclusion. Furthermore, specific binding of ${ }^{125} \mathrm{I}$-conjugated $\alpha$-bungarotoxin to junctional $\mathrm{ACh}$ receptors has been found to increase by about $88 \%$ between the ages of 10 and 28 months in this preparation (cf. Pestronk et al., 1980; Courtney and Steinbach, 1981; Smith and Chapman, 1987). This value corresponds well to the $73 \%$ increase in m.e.p.c. decay time following $\mathrm{AChE}$ inhibition in the older animals.

The data further indicate that an age-related increase in junctional $\mathrm{ACh}$ receptors probably involves an expanded receptor field rather than an increase in receptor density. The m.e.p.c. time to peak reflects indirectly the postsynaptic receptor area covered by a quantum of ACh (Hartzell et al., 1975). In the 10 month rats, the times to peak were the same before and after $\mathrm{AChE}$ inhibition, indicating that a quantum of $\mathrm{ACh}$ has affected the same receptive field. However, in the 26 month rats, the time to peak increased by nearly $70 \%$ following AChE inhibition. It may be inferred that the $\mathrm{ACh}$ receptor field is therefore also larger in the older animals.

In contrast, the data are not consistent with an age-related change in receptor density. If the density were greater, then after AChE inhibition the probability of ACh binding to a receptor should increase, and this should result in a more rapid increase in m.e.p.c. amplitude (Land et al., 1980). However, these rates were 5.6 and $6.0 \mathrm{nA} / \mathrm{msec}$ in the 10 and the 26 month animals, respectively. This similarity indicates that receptor densities must also be comparable.

Ultimately, increased $\mathrm{AChE}$ activity must result from either enhanced synthesis or reduced degradation. In cultured chick skeletal muscle and spinal cords, $\mathrm{ACh}$ or its analog acetyl- $\beta$ methylcholine have been shown to induce $\mathrm{AChE}$ activity (Oh and Johnson, 1972) or to retard AChE catabolism (Turbow and Burkhalter, 1968; Wilson et al., 1973), thus increasing AChE levels. There is significantly greater ACh leakage into the extracellular compartment at the diaphragm neuromuscular junction of older rats (Smith, 1984; Smith and Weiler, 1987). By inference, then, elevated AChE activities in the aged rats may be a physiological consequence of an age-related increase in presynaptic permeability to $\mathrm{ACh}$. Clearly, however, this hypothesis must be tested.

\section{References}

Bendat, J. S., and A. G. Piersol (1971) Random Data: Analysis and Measurement Procedures, pp. 323-325, Wiley, New York.

Courtney, J., and J. H. Steinbach (1981) Age changes in neuromuscular junction morphology and acetylcholine receptor distribution on rat skeletal muscle fibres. J. Physiol. (Lond.) 320: 435-447.

Dreyfus, P. A., A. Friboulet, L. H. Tran, and F. Rieger (1984) Poly- 
morphism of acetylcholinesterase and identification of new molecular forms after sedimentation analysis. Biol. Cell 51: 35-42.

Engel, A. G., E. H. Lambert, and T. Santa (1973) Study of long-term anticholinesterase therapy. Neurology 23: 1273-1281.

Fahim, M. A., J. A. Holley, and N. Robbins (1983) Scanning and light microscopic study of age changes at a neuromuscular junction in the mouse. J. Neurocytol. 12: 13-25.

Finney, D. J. (1978) Statistical Method in Biological Assay, 3rd ed., pp. 80-86, Griffin, London.

Glazer, E. J., T. Baker, and W. F. Riker (1978) The neuropathology of DFP at cat soleus neuromuscular junction. J. Neurocytol. 7: 741758.

Hartzell, H. C., S. W. Kuffler, and D. Yoshikami (1975) Post-synaptic potentiation: Interaction between quanta of acetylcholine at the skeletal neuromuscular synapse. J. Physiol. (Lond.) 251: 427-463.

Johnson, C. D., and R. L. Russell (1975) A rapid, simple radiometric assay for cholinesterase, suitable for multiple determinations. Anal. Biochem. 64: 229-238.

Katz, B., and R. Miledi (1973) The binding of acetylcholine to receptors and its removal from the synaptic cleft. J. Physiol. (Lond.) 231: 549-574.

Kordas, M. (1977) On the role of junctional cholinesterase in determining the time course of the end-plate current. J. Physiol. (Lond.) 270: 133-150.

Land, B. R., E. E. Salpeter, and M. M. Salpeter (1980) Acetylcholine receptor site density affects the rising phase of miniature endplate currents. Proc. Natl. Acad. Sci. USA 77: 3736-3740.

Laskowski, M. B., W. H. Olson, and W-D. Dettbarn (1975) Ultrastructural changes at the motor end-plate produced by an irreversible cholinesterase inhibitor. Exp. Neurol. 47: 290-306.

Leonard, J. P., and M. M. Salpeter (1979) Agonist-induced myopathy at the neuromuscular junction is mediated by calcium. J. Cell Biol. 82: 811-819.

Magleby, K. L., and C. F. Stevens (1972) The effects of voltage on the time course of end-plate currents. J. Physiol. (Lond.) 223: 151-171.

Massoulie, J., and S. Bon (1982) The molecular forms of cholinesterase and acetylcholinesterase in vertebrates. Annu. Rev. Neurosci. 5: 595605 .
Oh, T. H., and D. D. Johnson (1972) Effects of acetyl- $\beta$-methylcholine on development of acetylcholinesterase and butyrylcholinesterase activities in cultured chick embryonic skeletal muscle. Exp. Neurol. 37: 360-370.

Pestronk, A., D. B. Drachman, and J. W. Griffin (1980) Effects of aging on nerve sprouting and regeneration. Exp. Neurol. 70:65-82.

Rand, J. B., and F. J. Huff (1986) Use of a radiometric assay for butyrylcholinesterase to characterize the enzyme from human CSF. Soc. Neurosci. Abstr. 12: 889.

Rand, J. B., and C. D. Johnson (1981) A single-vial biphasic liquid extraction assay for choline acetyltransferase using $\left[{ }^{3} \mathrm{H}\right]$ choline. Anal. Biochem. 116: 361-371.

Rosenheimcr, J. L., and D. O. Smith (1985) Differential changes in the end-plate architecture of functionally diverse muscles during aging. J. Neurophysiol. 53: 1567-1581.

Smith, D. O. (1979) Reduced capabilities of synaptic transmission in aged rats. Exp. Neurol. 66: 650-666.

Smith, D. O. (1982) Restricted diffusion of extracellular potassium at the neuromuscular junction of aged rats. Brain Res. 239: 668-673.

Smith, D. O. (1984) Acetylcholine storage, release and leakage at the neuromuscular junction of mature adult and aged rats. J. Physiol. (Lond.) 347: 161-176.

Smith, D. O., and M. R. Chapman (1987) Acetylcholine receptor binding properties at the rat neuromuscular junction during aging. $J$. Neurochem. 48: 1834-1841.

Smith, D. O., and J. L. Rosenheimer (1982) Decreased sprouting and degeneration of nerve terminals of active muscles in aged rats. $J$. Neurophysiol. 48: 100-109.

Smith, D. O., and M. H. Weiler (1987) Acetylcholine metabolism and choline availability at the neuromuscular junction of mature adult and aged rats. J. Physiol. (Lond.) 383: 693-709.

Turbow, M. M., and A. Burkhalter (1968) Acetylcholinesterase activity in the chick embryo spinal cords. Dev. Biol. 17: 233-244.

Wang, C.-S., and R. L. Smith (1975) Lowry determination of protein in the presence of Triton X-100. Anal. Biochem. 63: 414-417.

Wilson, B. W., P. S. Nieberg, C. R. Walker, T. A. Linkhart, and D. M. Fry (1973) Production and release of acetylcholinesterase by cultured chick embryo muscle. Dev. Biol. 33: 285-299. 